\title{
Microstructure and Flow Stress of Nanoscale Cu/Nb Multilayers
}

\author{
F. Wang, ${ }^{1}$ L. F. Zhang, ${ }^{2}$ P. Huang, ${ }^{2}$ J. Y. Xie, ${ }^{2}$ T. J. Lu, ${ }^{1}$ and K. W. Xu ${ }^{2}$ \\ ${ }^{1}$ State Key Laboratory for Strength and Vibration of Mechanical Structures, School of Aerospace, \\ Xian Jiaotong University, Xian 710049, China \\ ${ }^{2}$ State Key Laboratory for Mechanical Behavior of Material, Xian Jiaotong University, Xian 710049, China \\ Correspondence should be addressed to F. Wang; wangfei@mail.xjtu.edu.cn and P. Huang; huangping@mail.xjtu.edu.cn
}

Received 2 April 2013; Accepted 11 May 2013

Academic Editor: Sheng-Rui Jian

Copyright (C) 2013 F. Wang et al. This is an open access article distributed under the Creative Commons Attribution License, which permits unrestricted use, distribution, and reproduction in any medium, provided the original work is properly cited.

Nanoscale $\mathrm{Cu} / \mathrm{Nb}$ multilayers with individual layer thicknesses of 2,5 , and $15 \mathrm{~nm}$ were prepared by d.c. magnetron sputtering. The cross-sectional morphologies of the multilayers were examined under transmission electron microscopy (TEM) as well as high resolution TEM, whilst the flow stresses were measured with nanoindentation. A unique cross-sectional microstructure comprising well-modulated and mixed regions was observed, causing length-scale-independent flow stresses not found in existing studies, and shear bands were absent upon plastic deformation. Built upon this unique microstructure, possible mechanisms underlying the high plastic stability and length-scale-independent flow stresses of $\mathrm{Cu} / \mathrm{Nb}$ multilayers were discussed in terms of amorphous-crystalline interface and its interaction with both mixed and well-modulated regions.

\section{Introduction}

Metallic multilayers have attracted much attention in recent decades for their unique mechanical properties. Particularly, multilayers with nanoscale individual layer thickness often exhibited ultrahigh strength at room temperature, about 1/3 $1 / 2$ of the theoretical strength $(\sim E / 30)[1-3]$. However, the limited ductility of nanoscale metallic multilayers, often less than $5 \%$, due to localized deformation, that is, shear bands (SBs), has been a major obstacle for their potential applications.

Recently, the formation of SBs in metallic multilayers became a hot topic, as it has been observed in numerous multilayer systems, for example, $\mathrm{Cu} / \mathrm{Nb}, \mathrm{Au} / \mathrm{Cu}$, and $\mathrm{Cu} / \mathrm{Ta}$ multilayers [4-8]. It has been well documented that SBs would form in such a multilayer only if its individual layer thickness, $h$, was smaller than a critical value. Several deformation mechanisms have been proposed to interpret the unique localized deformation at reduced microstructural length scales. First of all, the lack of work hardening in multilayers with reduced nanoscale $h$ was proposed to play an important role in forming SBs [7]: decreasing the capacity and mobility of dislocations could result in prevalent grain boundary (GB) mediated processes [9-11], which dominated the plastic deformation of the multilayers. On the other hand, atomic simulations predicted that the production and storage of dislocations at the interface may weaken the interface of a multilayer, eventually causing SBs to be formed and transferred across the interface unsteadily [12].

Despite individual layer thickness $[4,5,8]$, it was proposed that interface structure [5] and grain morphology [13] also affected significantly the forming of SBs in multilayers. Specifically, for the effects of interface structure, SBs were observed in nanoscale $\mathrm{Cu} / \mathrm{Nb}$ multilayers with fcc/bcc interface but not in $\mathrm{Cu} / \mathrm{Ni}$ with $\mathrm{fcc} / \mathrm{fcc}$ interface [5]. In another study, however, a higher resistance to plastic instability was found in nanoscale $\mathrm{Cu} / \mathrm{Cr}$ multilayers with $\mathrm{fcc} / \mathrm{bcc}$ interface in comparison with $\mathrm{Cu} / \mathrm{Au}$ multilayers possessing fcc/ fcc interface [6]. Apparently, controversies still remain and further studies are needed to clarify the mechanisms of resistance to localized deformation in nanoscale multilayers.

In this paper, $\mathrm{Cu} / \mathrm{Nb}$ multilayers with varying individual layer thicknesses were selected to investigate the plastic instability and flow stress of nanoscale metallic multilayers. Different from existing studies, we identified an abnormal microstructure which could lead to significantly enhanced plastic stability, resulting in length-scale-independent flow stresses in $\mathrm{Cu} / \mathrm{Nb}$ multilayers. 


\section{Experiments}

$\mathrm{Cu} / \mathrm{Nb}$ multilayers were deposited by d.c. magnetron sputtering on silicon substrates at room temperature. The chamber was evacuated to a base pressure less than $5 \times 10^{-7}$ mbar, whilst the sputtering pressure of $\mathrm{Ar}$ was fixed at $6.3 \times$ $10^{-3}$ mbar. The substrate was neither heated nor cooled during deposition, with deposition rates fixed at $0.2 \mathrm{~nm} / \mathrm{s}$ for $\mathrm{Cu}$ and $0.12 \mathrm{~nm} / \mathrm{s}$ for $\mathrm{Nb}$. Both $\mathrm{Cu}$ and $\mathrm{Nb}$ layers had equal thickness, and three individual layer thicknesses were selected: 2, 5, and $15 \mathrm{~nm}$ (referred hereafter as CN2, CN5, and $\mathrm{CN15}$ ). The total thickness of all the multilayers was $800 \mathrm{~nm}$.

To observe the modulation structure and microstructural details of the as-deposited multilayers, transmission electron microscopy (TEM) and high resolution TEM (HRTEM) were conducted in a JEM $2100 \mathrm{~F}$ operated at $200 \mathrm{kV}$ accelerating voltages.

The mechanical properties of the multilayers were investigated by Nano Indenter XP system (MTS, Inc.) at room temperature using a continuous stiffness measurement (CSM) mode at a strain rate of $0.05 \mathrm{~s}^{-1}$. A Berkovich indenter was used in all the experiments. Whilst the maximum indentation depth was fixed at $400 \mathrm{~nm}$, at least 13 bilayer thicknesses were penetrated for the multilayers having maximum individual layer thickness. During loading, hardness was automatically recorded with the CSM mode as a continuous function of surface penetration depth. To avoid any substrate effect, the hardness of the multilayers was calculated by averaging the values of the hardness obtained within a depth range from $50 \mathrm{~nm}$ to $100 \mathrm{~nm}$. A minimum of 10 indents were performed on each multilayer. Finally, the indentation morphologies were observed using scanning electron microscopy (SEM, Quanta 600FEG).

\section{Results}

HRTEM cross-sectional images of the $\mathrm{Cu} / \mathrm{Nb}$ multilayers are shown in Figures 1(a) to 1(c). For CN2 and CN5 multilayers, the expected modulated structure generally observed in $\mathrm{Cu} / \mathrm{Nb}$ multilayers broke down, as some regions with a wellmodulated structure were surrounded by regions having a mixed structure. As shown in the HRTEM images presented in Figures 2 and 3, the mixed regions were amorphous in both $5 \mathrm{~nm}$ (except some small areas marked by the yellow arrow in Figure 3(a)) and $2 \mathrm{~nm}$ layered multilayers. To the best of the authors' knowledge, this kind of microstructure has not been reported in the open literature for nanoscale metallic multilayers. This phenomenon might be a result of the coalescence of the islands during sputtering. For sputtering very thin layers, individual islands would form, followed by gradual coalescence of such individual islands. The interface of two islands could be amorphous. Once the layer thickness becomes higher, such amorphous regions would be self-adjust to form the regular crystalline planner layers. One would then naturally expect that multilayers with such unique microstructure may exhibit unusual deformation behaviors. Interestingly, in contrary to observations that abundant SBs appeared during indentation in nanoscale $\mathrm{Cu} / \mathrm{Nb}$ multilayers $[4,5]$, no shear banding deformation was
TABLE 1: Hardness, elastic modulus, and flow stress of the CN2, CN5, and CN15 multilayers.

\begin{tabular}{lccc}
\hline Sample & $\begin{array}{c}\text { Hardness } \\
(\mathrm{GPa})\end{array}$ & $\begin{array}{c}\text { Elastic modulus } \\
(\mathrm{GPa})\end{array}$ & $\begin{array}{c}\text { Flow stress } \\
(\mathrm{GPa})\end{array}$ \\
\hline CN2 & $7.76 \pm 0.35$ & $153.20 \pm 1.47$ & 2.87 \\
CN5 & $7.86 \pm 0.14$ & $166.39 \pm 0.76$ & 2.91 \\
CN15 & $7.96 \pm 0.13$ & $179.66 \pm 1.74$ & 2.95 \\
\hline
\end{tabular}

observed in indention morphologies obtained for the present $\mathrm{Cu} / \mathrm{Nb}$ multilayers, as shown in Figures 1(d) to 1(f). Moreover, there was even no pile up around residual indentions.

To further explore the unusual microstructure, energy disperse spectroscopy (EDS) was performed to examine the distribution of $\mathrm{Cu}$ and $\mathrm{Nb}$ in both mixed region and modulated region, which had quite different morphologies, especially $\mathrm{CN} 5$ and $\mathrm{CN} 2$ multilayers. Whilst $\mathrm{Cu}$ and $\mathrm{Nb}$ layers were distributed periodically in the modulated region of CN5 as shown in Figures 2(b) and 3(a), the two layers were severely mixed up in the mixed region as shown in Figure 2(c). However, for $\mathrm{CN} 15$ multilayers, no such mixed region was observed.

The hardness, elastic modulus, and flow stress of the CN2, $\mathrm{CN} 5$, and $\mathrm{CN} 15$ multilayers derived from the nanoindentation test were shown in Table 1. Figure 4 presents the flow stresses of the present multilayers estimated via dividing the measured indentation hardness by a factor of 2.7; for comparison, results reported previously $[4,14]$ are also included. It was seen from Figure 4 that when the individual layer thickness was reduced from $15 \mathrm{~nm}$ to $2 \mathrm{~nm}$, the flow stresses of the three $\mathrm{Cu} / \mathrm{Nb}$ multilayers examined in the current study remained nearly unchanged. This observation was quite different from the general trend previously observed in $\mathrm{Cu} / \mathrm{Nb}$ multilayers having identical length scale: increasing strength with decreasing individual layer thickness $[4,14]$; see Figure 4.

\section{Discussion}

4.1. Cross-Sectional Morphology-Dependent Plastic Stability. With individual layer thickness $(h)$ reduced to tens or a few nanometers, numerous studies have demonstrated that shear banding deformation would occur in multilayers, for example, $\mathrm{Cu} / \mathrm{Ta}[8], \mathrm{Cu} / \mathrm{Au}[6,7]$, and $\mathrm{Cu} / \mathrm{Nb}[4,5]$ multilayers. For a typical example, shear bands formed easily in $\mathrm{Cu} / \mathrm{Nb}$ multilayers with $h=5 \mathrm{~nm}$ in comparison with the case of $h=$ $20 \mathrm{~nm}$ [5]. The confined layer slip (CLS) model was proposed as the dominant mechanism in $20 \mathrm{~nm}$ layered multilayers [14, 15], causing homogeneous deformation as single dislocation loops were confined in individual layers. This was consistent with the present observation that no shear band appeared in the present $\mathrm{CN} 15$ multilayers. Given that the periodical cross-sectional morphology of the CN15 multilayers was similar to the one reported in [5], the CLS model would still hold, leading to homogeneous plastic deformation in the multilayers.

For $\mathrm{Cu} / \mathrm{Nb}$ multilayers with $h=5 \mathrm{~nm}$, however, SBs were observed by Bhattacharyya et al. [5] but not in the present 


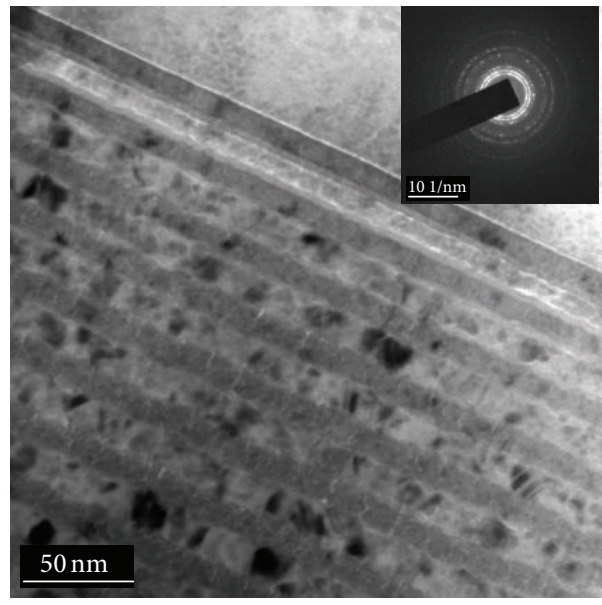

(a)

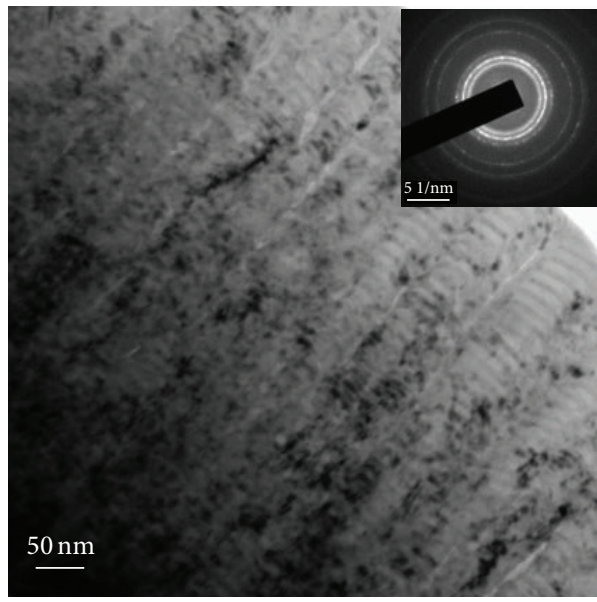

(b)

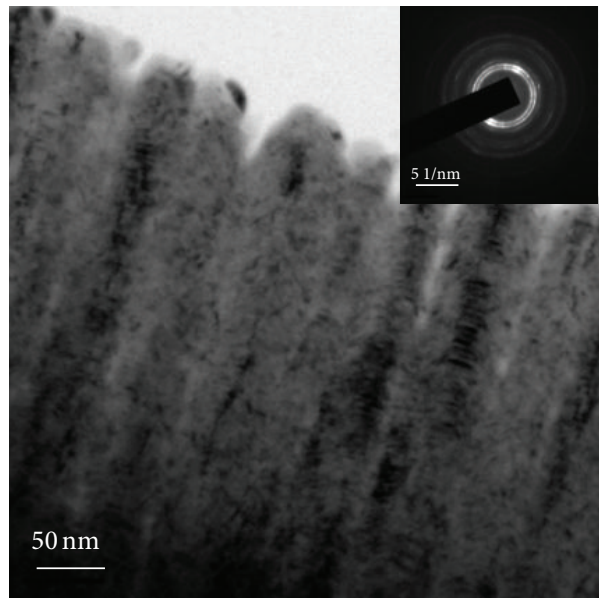

(c)

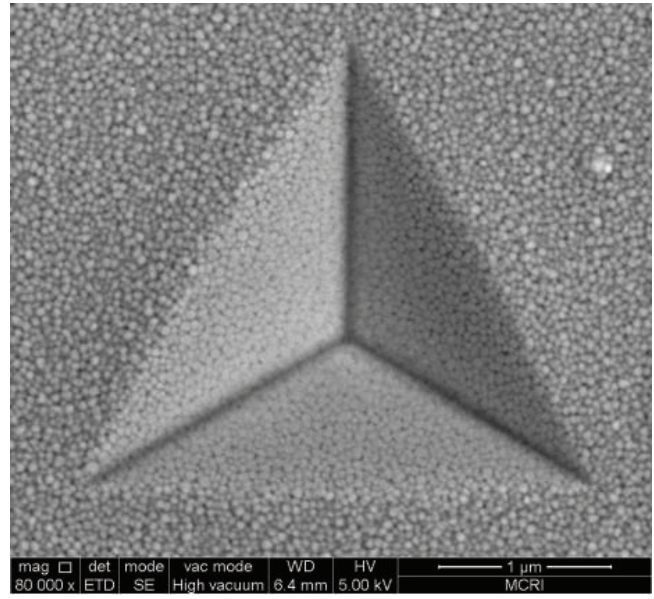

(d)

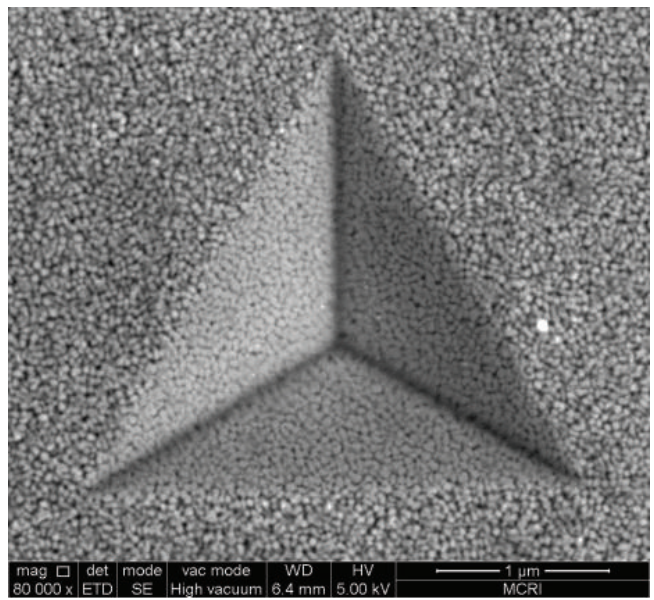

(e)

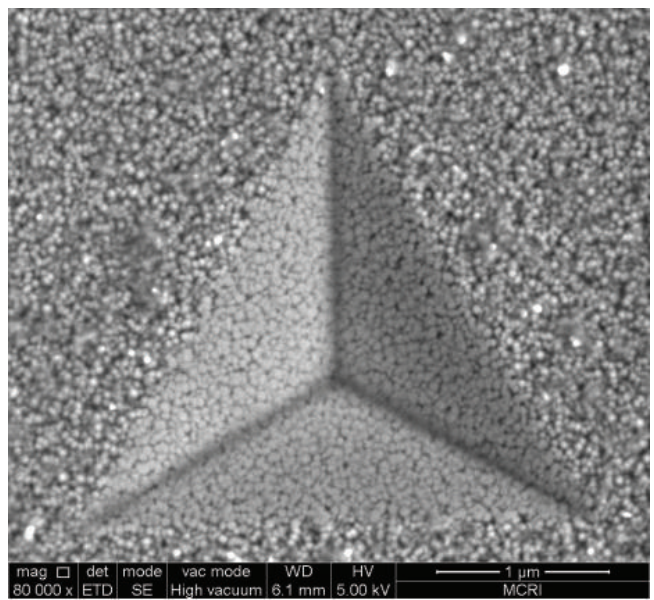

(f)

FIGURE 1: Cross-sectional TEM images of (a) CN15, (b) CN5, and (c) CN2 multilayers; corresponding SEM images of indention morphology for (d) CN15, (e) CN5, and (f) CN2 multilayers. 


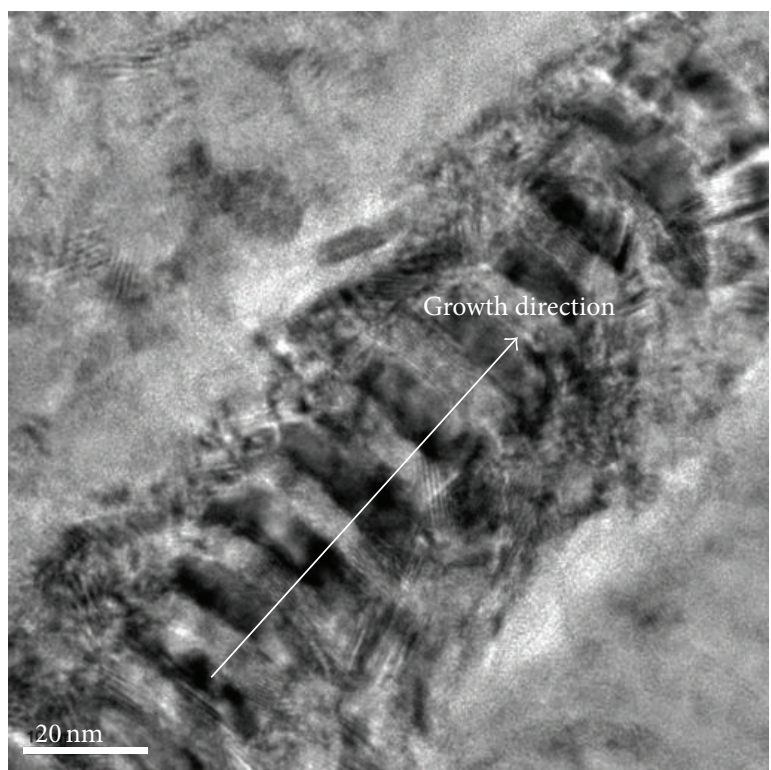

(a)

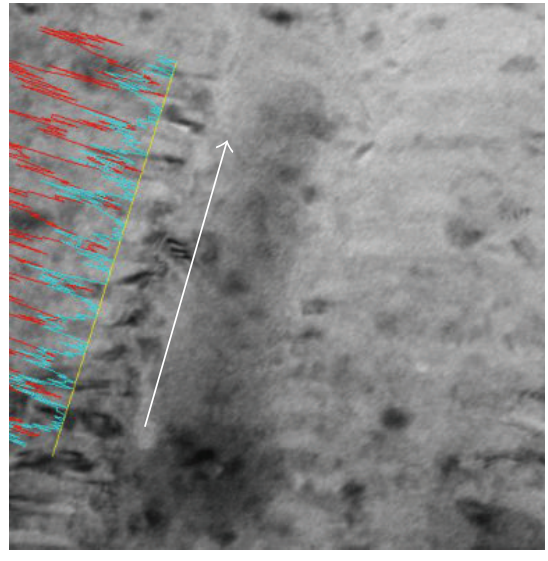

(b)

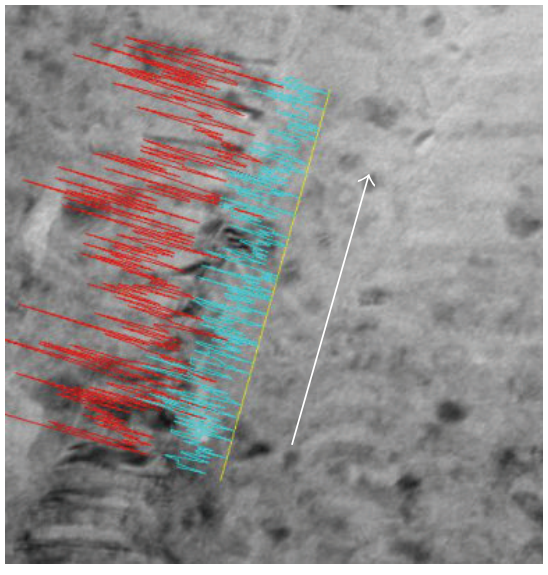

(c)

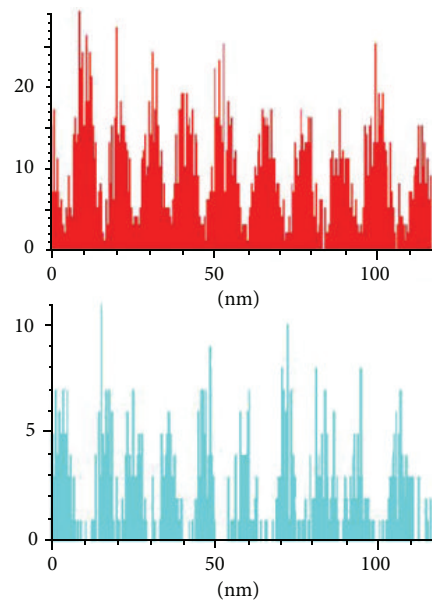

(d)
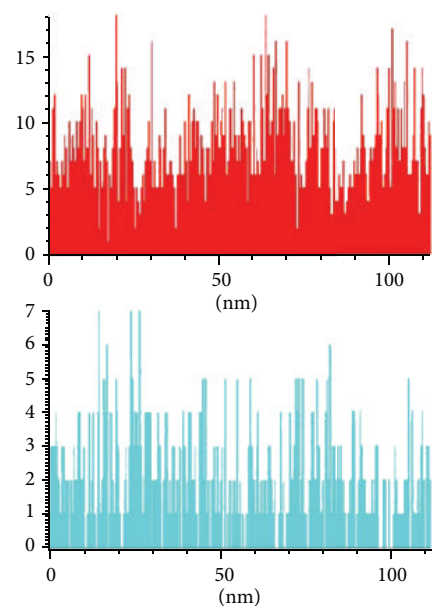

(e)

FIgURE 2: (a) High magnified TEM images of CN5 multilayers showing both modulated region and mixed region; EDS images of (b) modulated region and (c) mixed region. The white arrows indicated the growth direction of the multilayers. 


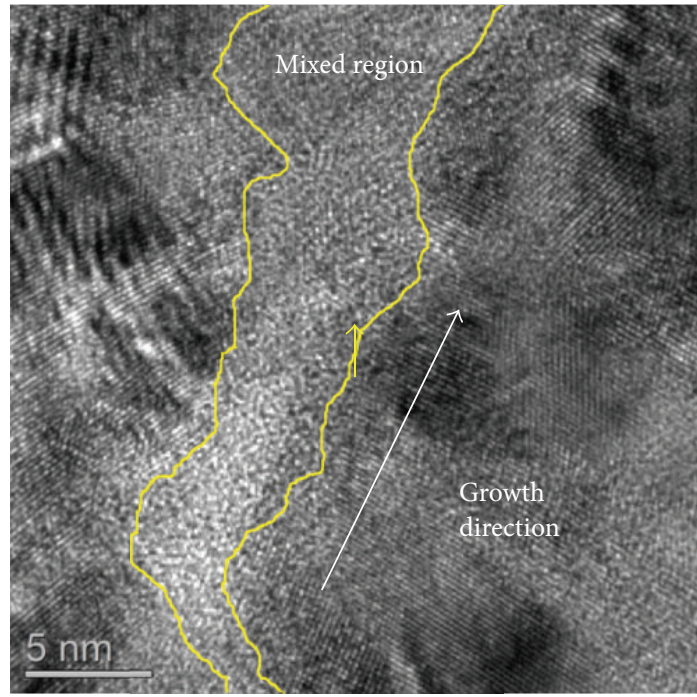

(a)

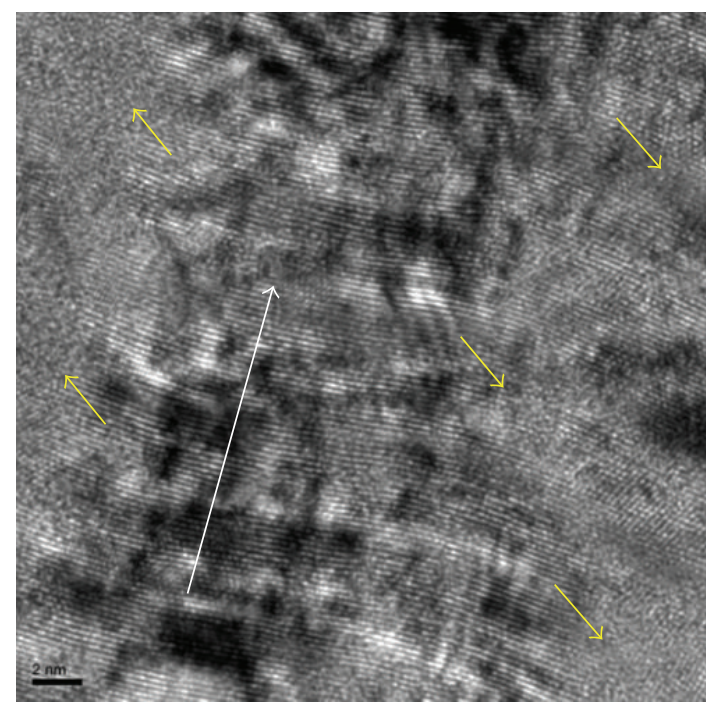

(b)

FIgURE 3: HRTEM images of (a) CN5 and (b) CN2 multilayers, with mixed region marked by yellow curves in (a) and yellow arrows in (b), respectively. The white arrows indicated the growth direction of the multilayers.

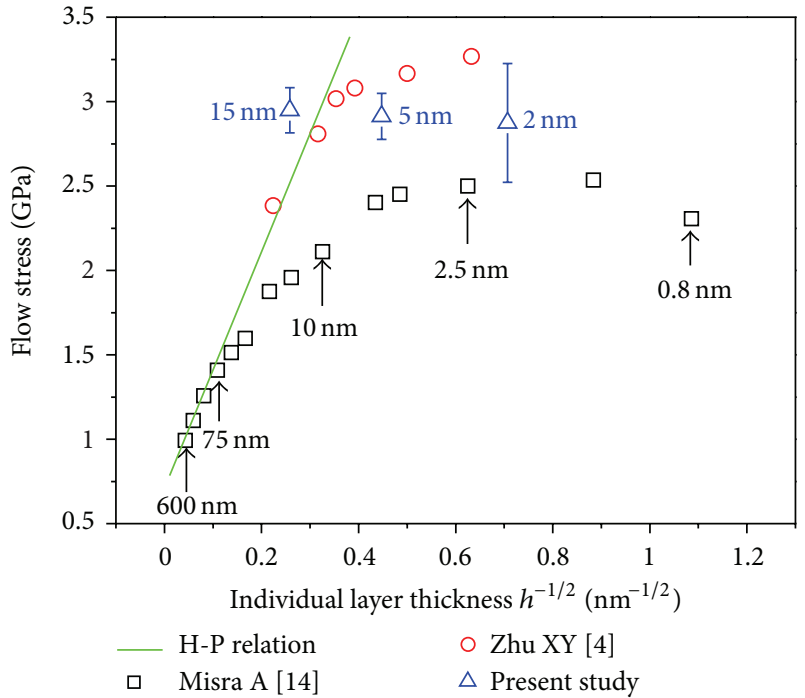

FIGURE 4: Flow stress of $\mathrm{Cu} / \mathrm{Nb}$ multilayers plotted as a function of individual layer thickness, with data reported by Zhu et al. [4] and Misra et al. [14] also included. All the test data presented were estimated as nanoindentation hardness divided by a factor of 2.7 ; the green line represented a linear fit of the Hall-Petch relation specifically for $\mathrm{Cu} / \mathrm{Nb}$ multilayers.

CN5 multilayers. Bhattacharyya et al. attributed the appearance of SB at relatively small individual layer thicknesses to mechanism transition from CLS model to interface cutting by single dislocation, for which the discontinuity of the slip planes between $\mathrm{Cu}$ and $\mathrm{Nb}$ induced shear instability by adequate amount of layer rotation [5]. In the same study, however, no SBs were observed in $\mathrm{Cu} / \mathrm{Ni}$ multilayers having either $h=4 \mathrm{~nm}$ or $17 \mathrm{~nm}$ [5]. Without providing clear explanation, Bhattacharyya and coauthors proposed two possible mechanisms for this unexpected contradiction: the difference in interfacial structure between $\mathrm{Cu} / \mathrm{Nb}$ and $\mathrm{Cu} / \mathrm{Ni}$ and the slower accumulation of dislocation debris in $\mathrm{Cu} / \mathrm{Ni}$ multilayers compared with $\mathrm{Cu} / \mathrm{Nb}$. However, there may exist another mechanism that could affect significantly the plastic stability of nanoscale metallic multilayers, as addressed in the following.

As shown in Figure 9 of Bhattacharyya et al. [5], even though the $\mathrm{Cu} / \mathrm{Ni}$ multilayers remained nearly intact, separated regions with wavy morphologies clearly existed, running across (nearly) the thickness direction in a way similar to the one observed in the present CN5 multilayers; see Figure 1(b). However, no apparent mixed regions were present between the separated regions in the $\mathrm{Cu} / \mathrm{Ni}$ multilayers [5] or V/Ag multilayers for which similar morphologies were reported [16]. At present, the formation of mixed region in $\mathrm{Cu} / \mathrm{Nb}$ multilayer is yet well understood, and this task is beyond the scope of this study. It is conceivable, however, that the formation of this unique cross-sectional morphology may contribute to the same kinetic behavior of the deposits (see [16] for details), as the three types of multilayers concerned here, $\mathrm{Cu} / \mathrm{Ni}$ [5], $\mathrm{V} / \mathrm{Ag}$ [16], and $\mathrm{Cu} / \mathrm{Nb}$, were all fabricated via the d.c. magnetron sputtering technique. It is worth mentioning that, in a separate nanoindentation study [4], SBs were found in $2.5 \mathrm{~nm}$ and $4 \mathrm{~nm}$ layered $\mathrm{Cu} / \mathrm{Nb}$ multilayers but not in those with $h \geq 6 \mathrm{~nm}$; however, no cross-sectional morphologies were provided.

The modulated structure of the present CN5 and CN2 multilayers was quite similar to the cross-sectional morphology of $\mathrm{Cu} / \mathrm{Ni}$ multilayers studied by Bhattacharyya et al. [5]. However, the former were clearly separated by mixed regions (see Figures 2 and 3) but not in the latter. This difference in cross-sectional morphologies between the two types of multilayers may be the new mechanism previously 


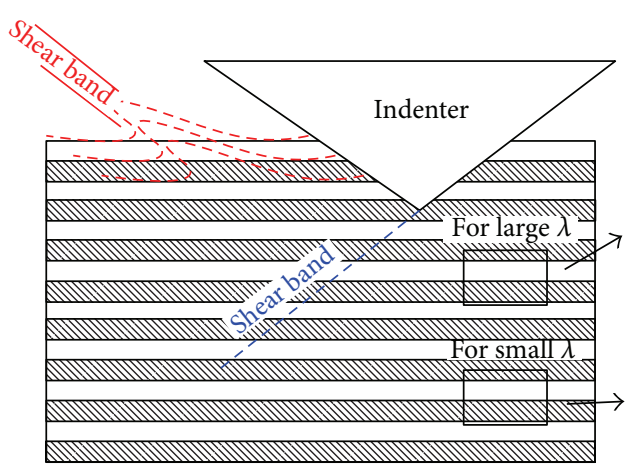

(a)

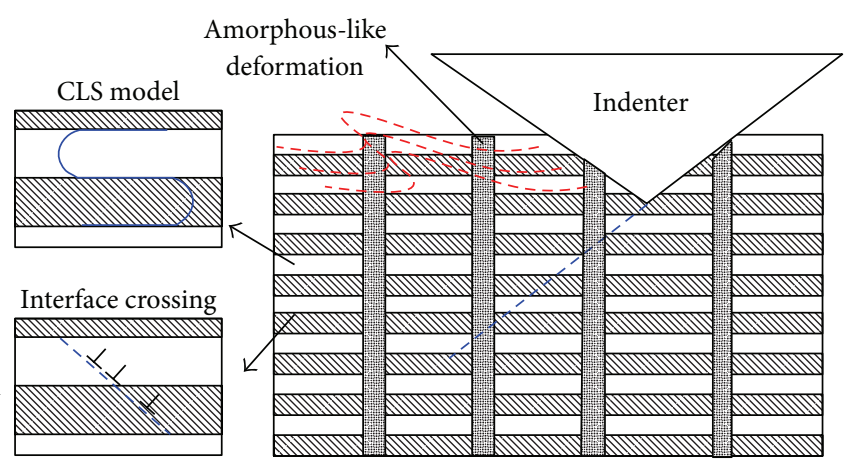

(b)

FIGURE 5: Schematic illustration of (a) dominant mechanism in forming SBs in metallic multilayers, and (b) confined modulated regions separated by mixed region proposed as a possible mechanism underlying the significantly enhanced plastic stability of $\mathrm{Cu} / \mathrm{Nb}$ multilayers.

mentioned, potentially playing a key role in determining plastic stability in nanoscale metallic multilayers.

The width of the modulated region in $5 \mathrm{~nm}$ layered $\mathrm{Cu} / \mathrm{Nb}$ multilayers was about $40-50 \mathrm{~nm}$, while the width of the mixed region was 5-10 nm; see Figure 1(b). Accordingly, the plastic deformation of the multilayers should be accommodated simultaneously by the two different kinds of regions. For the CN2 multilayers, whilst the mixed and modulated regions were not as well organized as those in CN5 shown in Figure 3(a), one could still clearly identify the mixed regions, as marked by yellow arrows in Figure 3(b). It should be mentioned that the volume fraction of the mixed region in the CN5 multilayers is roughly $\sim 10 \%$ to $\sim 20 \%$ based on the widths of those two regions. For the CN2 multilayers, however, the volume fractions of those two regions are hardly evaluated because of the sporadically spread mixed regions shown in Figure 3(b). Built upon this observation from the present CN5 and CN2 multilayers, Figures 5(a) and 5(b) illustrate schematically the mechanisms underlying the formation of SBs in multilayers and those mechanisms that are responsible for stabilizing the plastic deformation. For simplicity, Figure 5(b) was constructed mainly based on the morphology of CN5.

Because the width of amorphous-mixed regions was only about 5-10 nm, shear transformation zones (STZs), which has been considered as the main mechanism accommodating plastic deformation in amorphous materials [17], may not be able to develop into mature SBs in both CN5 and CN2 multilayers, since the size of the stressed amorphous region should exceed a characteristic length scale to form SBs [18]. For Zr-based metallic glass, such characteristic length scale was predicted as 5-10 $\mathrm{nm}$ [18], which was adopted herein as the parameters required to calculate the length scale of the present mixed region [19] are unknown. Besides, since the amorphous structure in the mixed region may also contain crystalline areas, it may not be an ideal amorphous structure as the Zr-based metallic glass. Therefore, the characteristic length scale for the present $\mathrm{Cu} / \mathrm{Nb}$ multilayers should be bigger than 5-10 $\mathrm{nm}$.

As pointed out before, interface crossing by dislocations [14] as shown in Figure 5(a) was proposed to be the dominant mechanism in forming SBs for nanoscale $\mathrm{Cu} / \mathrm{Nb}$ multilayers [5]. For the present $\mathrm{Cu} / \mathrm{Nb}$ multilayers having two different kinds of microstructural regions, even though interface crossing by dislocations may turn out to be an active deformation process, it could only occur in the modulated region but not in the mixed region. More importantly, the forming path of SBs, represented by dotted blue lines in Figure 5, would be interrupted by the mixed region, resulting in no $\mathrm{SB}$ as shown in Figure 1. In addition, the existence of the mixed region made it difficult for the modulated regions to rotate. Consequently, the mechanism of SBs induced by layer-rotation $[7,20]$ (marked by three red wary lines in the upper-left area of Figures 5(a) and 5(b)) would not occur in nanoscale $\mathrm{Cu} / \mathrm{Nb}$ multilayers.

\subsection{Plastic Deformation Associated with Amorphous-Crystal-} line Interfaces (ACIs). The strength of metallic multilayers is in general length scale dependent [14]: (1) the Hall-Petch (H$\mathrm{P})$ relation holds at microlength scale and above; (2) at submicrometer length scale, the H-P relation breaks down but the strength still increases as $h$ is decreased; and (3) inverse H-P relation occurs when $h$ is reduced to a few nanometers and below. In contrast, however, the flow stresses of the present $\mathrm{Cu} / \mathrm{Nb}$ multilayers plotted in Figure 4 were nearly constant as $h$ is reduced from $15 \mathrm{~nm}$ to $2 \mathrm{~nm}$. Interestingly, a similar trend was also found in $\mathrm{Cu} / \mathrm{Ni}$ multilayers [5] possessing similar cross-sectional morphologies as $\mathrm{Cu} / \mathrm{Nb}$, for example, hardness remained nearly unchanged (from $4 \mathrm{GPa}$ to $4.05 \mathrm{GPa}$ ) when $h$ was decreased from $17 \mathrm{~nm}$ to $3.9 \mathrm{~nm}$. The unusual length-scale-independent flow stress of nanoscale metallic multilayers may be attributed to their unique crosssectional morphologies, including mixed/modulated regions in the present $\mathrm{Cu} / \mathrm{Nb}$ multilayers and the wary morphology in $\mathrm{Cu} / \mathrm{Ni}$ multilayers [5].

For $\mathrm{Cu} / \mathrm{Nb}$ multilayers with $h$ of either $5 \mathrm{~nm}$ or $2 \mathrm{~nm}$, the amorphous-crystalline interfaces (ACIs) proposed by Wang et al. $[18,21]$ might affect the flow stress significantly. It was demonstrated by molecular dynamic simulations that ACIs could act as sources and sinks of dislocations in multilayers to mediate plastic shear/slip transfer and eliminate stress concentration in GB triple junctions [18]. Therefore, three 
different types of interface, namely, ACIs, heterogeneous crystalline-crystalline interfaces (CCIs), and GBs, may coexist in the present $5 \mathrm{~nm}$ and $2 \mathrm{~nm}$ layered multilayers.

For CN15 multilayers, as shown in Figure 4, although slightly higher than that predicted by the H-P relation for $\mathrm{Cu} / \mathrm{Nb}$ multilayers [14], its flow stress was comparable with that reported by Zhu et al. [4] who found that the H-P relation holds even at much smaller $h$ values than those provided by Misra et al. [14]. Therefore, dislocation pileup should still be functioning in CN15 multilayers, with its plastic deformation dominated by the CLS model because of its well-organized alternative layers.

As $h$ was reduced from $15 \mathrm{~nm}$ to $5 \mathrm{~nm}$ and $2 \mathrm{~nm}$ (i.e., CN5 and CN2), the presence of the unique mixed region broke the continuity of alternative layers. Previously, it has been shown that the stress required for dislocation nucleation from ACIs was lower than that from CCI and GBs [21]. Moreover, the slip/shear transfer occurring at ACIs was very different from that at CCIs and GBs. For plastic deformation at GBs or CCIs, slip/shear transfer appeared either by core spreading along the shear-weak interface or by triggering new slip planes with a specific Schmidt factor. Accordingly, large geometrical incompatibility and stress concentration would form near the GBs or CCIs. Consequently, relative to the other two kinds of interfaces, ACIs was the preferable source for dislocation nucleation and emission. The existence of ACIs in CN5 and CN2 multilayers would thence reduce the flow stress, compensating the increasing of flow stress due to reduced $h$. For CN2 multilayers, as shown in Figure 3(b), the mixed regions were distributed more randomly than those in CN5 (where the mixed and modulated regions were alternatively organized). The randomly distributed mixed regions may be the main cause for the relatively large error bar of the flow stress measurement for $\mathrm{CN} 2$ in comparison with other two multilayers (CN15 and CN5); see Figure 4. What is more, the dimension of mixed region in CN5 is greater than that in $\mathrm{CN} 2$. This may also relate to the interlayer diffusion during sputtering. The growth of film is through layer-by-layer plus island growth [22]. Surface diffusion, the Ehrlich-Schwoebel (ES) effect, and deposition rate may affect the mobility of deposited atoms. The surface diffusion is a smoothing process, which results in reduced surface curvature. However, the ES effect is a roughening mechanism, which inhibits the moving of diffusing atoms. The growth of films is a process of the competition of these two mechanisms. Compared with $\mathrm{CN15}$, when the deposit time for individual layer thickness is short, that is, for CN2 and CN5 in the present study, the surface diffusion cannot smooth the islands, while ES effect results in enhanced curving interface. The atoms will diffuse along the vertical direction near the step edges of some certain islands, which resulted in the observed mixed regions in CN2 and CN5 multilayers. When the individual layer thickness is small, the diffusion area near the step edges should be much narrower than that in larger individual layer thickness, making the mixed region in CN2 smaller than that in CN5.

4.3. Further Remarks. As mentioned above, the $\mathrm{Cu} / \mathrm{Ni}$ multilayers reported by Bhattacharyya et al. [5] exhibited similarities with the present $\mathrm{Cu} / \mathrm{Nb}$ multilayers, including both cross-sectional morphology and length-scale-independent flow stress. Although mixed regions were observed in $\mathrm{Cu} / \mathrm{Nb}$ but not in $\mathrm{Cu} / \mathrm{Ni}$, the modulated regions in both multilayers were well separated from each other. In addition, since contradicting observations regarding plastic stability of $\mathrm{Cu} / \mathrm{Nb}$ multilayers at identical length scale have been reported by Bhattacharyya et al. [5] and the present work, one may argue that the breaking down of well-modulated multilayers into isolated regions plays a key role in preventing plastic instability in nanoscale multilayers. Further studies, both experimentally and theoretically, are apparently needed to clarify the contribution of the unique microstructure.

\section{Conclusion}

The microstructure and flow stress of nanoscale $\mathrm{Cu} / \mathrm{Nb}$ multilayers fabricated by sputtering deposition were studied using TEM and nanoindentation. For relatively small individual layer thicknesses ( $5 \mathrm{~nm}$ and $2 \mathrm{~nm}$ ), a unique crosssectional microstructure comprising two different phases, that is, mixed region and modulated region, was observed. This novel microstructure played a decisive role in enhancing plastic stability, leading to length-scale-independent flow stresses different from existing data. For enhanced plastic stability, it was proposed that the forming paths of SB proposed in previous studies broke down as the modulated regions were confined and separated by mixed regions. As a potential mechanism underlying the length-scale-independent flow stresses, it was proposed that the existence of ACIs between the mixed and modulated regions reduced the flow stress, which compensated the increasing of flow stress due to reduced individual layer thickness.

\section{Acknowledgments}

This work was financially supported by the National Basic Research Program of China (2010CB631002, 2011CB610306), the National Natural Science Foundation of China (51171141, 51271141), the Program for New Century Excellent Talents in University (NCET-11-0431), the Research Fund for the Doctoral Program of Higher Education of China (20120201110001), and the Fundamental Research Funds for the Central Universities.

\section{References}

[1] K. O. Schweitz, J. Chevallier, J. Bottiger, W. Matz, and N. Schell, "Hardness in $\mathrm{Ag} / \mathrm{Ni}, \mathrm{Au} / \mathrm{Ni}$ and $\mathrm{Cu} / \mathrm{Ni}$ multilayers," Philosophical Magazine A, vol. 81, no. 8, pp. 2021-2032, 2001.

[2] A. Misra, M. Verdier, Y. C. Lu et al., "Structure and mechanical properties of $\mathrm{Cu}-\mathrm{X}(\mathrm{X}=\mathrm{Nb}, \mathrm{Cr}, \mathrm{Ni})$ nanolayered composites," Scripta Materialia, vol. 39, no. 4-5, pp. 555-560, 1998.

[3] J. McKeown, A. Misra, H. Kung, R. G. Hoagland, and M. Nastasi, "Microstructures and strength of nanoscale $\mathrm{Cu}-\mathrm{Ag}$ multilayers," Scripta Materialia, vol. 46, no. 8, pp. 593-598, 2002.

[4] X. Y. Zhu, J. T. Luo, F. Zeng, and F. Pan, "Microstructure and ultrahigh strength of nanoscale $\mathrm{Cu} / \mathrm{Nb}$ multilayers," Thin Solid Films, vol. 520, no. 2, pp. 818-823, 2011.

[5] D. Bhattacharyya, N. A. Mara, P. Dickerson, R. G. Hoagland, and A. Misra, "Transmission electron microscopy study of 
the deformation behavior of $\mathrm{Cu} / \mathrm{Nb}$ and $\mathrm{Cu} / \mathrm{Ni}$ nanoscale multilayers during nanoindentation," Journal of Materials Research, vol. 24, no. 3, pp. 1291-1302, 2009.

[6] Y. P. Li, X. F. Zhu, J. Tan, B. Wu, W. Wang, and G. P. Zhang, "Comparative investigation of strength and plastic instability in $\mathrm{Cu} / \mathrm{Au}$ and $\mathrm{Cu} / \mathrm{Cr}$ multilayers by indentation," Journal of Materials Research, vol. 24, no. 3, pp. 728-735, 2009.

[7] G. P. Zhang, Y. Liu, W. Wang, and J. Tan, "Experimental evidence of plastic deformation instability in nanoscale $\mathrm{Au} / \mathrm{Cu}$ multilayers," Applied Physics Letters, vol. 88, no. 1, Article ID 013105, 2006.

[8] F. Wang, P. Huang, M. Xu, T. J. Lu, and K. W. Xu, "Shear banding deformation in $\mathrm{Cu} / \mathrm{Ta}$ nano-multilayers," Materials Science and Engineering A, vol. 528, no. 24, pp. 7290-7294, 2011.

[9] M. A. Meyers, A. Mishra, and D. J. Benson, "Mechanical properties of nanocrystalline materials," Progress in Materials Science, vol. 51, no. 4, pp. 427-556, 2006.

[10] H. Van Swygenhoven and P. M. Derlet, "Grain-boundary sliding in nanocrystalline fcc metals," Physical Review B, vol. 64, no. 22, Article ID 224105, 9 pages, 2001.

[11] H. Van Swygenhoven, M. Spaczer, and A. Caro, "Microscopic description of plasticity in computer generated metallic nanophase samples: a comparison between $\mathrm{Cu}$ and Ni," Acta Materialia, vol. 47, no. 10, pp. 3117-3126, 1999.

[12] J. Wang, R. G. Hoagland, and A. Misra, "Room-temperature dislocation climb in metallic interfaces," Applied Physics Letters, vol. 94, no. 13, Article ID 131910, 2009.

[13] S. P. Wen, F. Zeng, F. Pan, and Z. R. Nie, "The influence of grain morphology on indentation deformation characteristic of metallic nano-multilayers," Materials Science and Engineering A, vol. 526, no. 1-2, pp. 166-170, 2009.

[14] A. Misra, J. P. Hirth, and R. G. Hoagland, "Length-scaledependent deformation mechanisms in incoherent metallic multilayered composites," Acta Materialia, vol. 53, no. 18, pp. 4817-4824, 2005.

[15] A. Misra and H. Kung, "Deformation behavior of nanostructured metallic multilayers," Advanced Engineering Materials, vol. 3, no. 4, pp. 217-222, 2001.

[16] Q. M. Wei and A. Misra, "Transmission electron microscopy study of the microstructure and crystallographic orientation relationships in V/Ag multilayers," Acta Materialia, vol. 58, no. 14, pp. 4871-4882, 2010.

[17] C. A. Schuh, T. C. Hufnagel, and U. Ramamurty, "Mechanical behavior of amorphous alloys," Acta Materialia, vol. 55, no. 12, pp. 4067-4109, 2007.

[18] Y. Wang, J. Li, A. V. Hamza, and T. W. Barbee, "Ductile crystalline-amorphous nanolaminates," Proceedings of the National Academy of Sciences of the United States of America, vol. 104, no. 27, pp. 11155-11160, 2007.

[19] F. Shimizu, S. Ogata, and J. Li, "Yield point of metallic glass," Acta Materialia, vol. 54, no. 16, pp. 4293-4298, 2006.

[20] Y. P. Li, J. Tan, and G. P. Zhang, "Interface instability within shear bands in nanoscale Au/Cu multilayers," Scripta Materialia, vol. 59, no. 11, pp. 1226-1229, 2008.

[21] Y. M. Wang, A. V. Hamza, and T. W. Barbee, "Incipient plasticity in metallic glass modulated nanolaminates," Applied Physics Letters, vol. 91, no. 6, Article ID 061924, 2007.

[22] Q. Wei and A. Misra, “Transmission electron microscopy study of the microstructure and crystallographic orientation relationships in V/Ag multilayers," Acta Materialia, vol. 58, no. 14, pp. 4871-4882, 2010. 

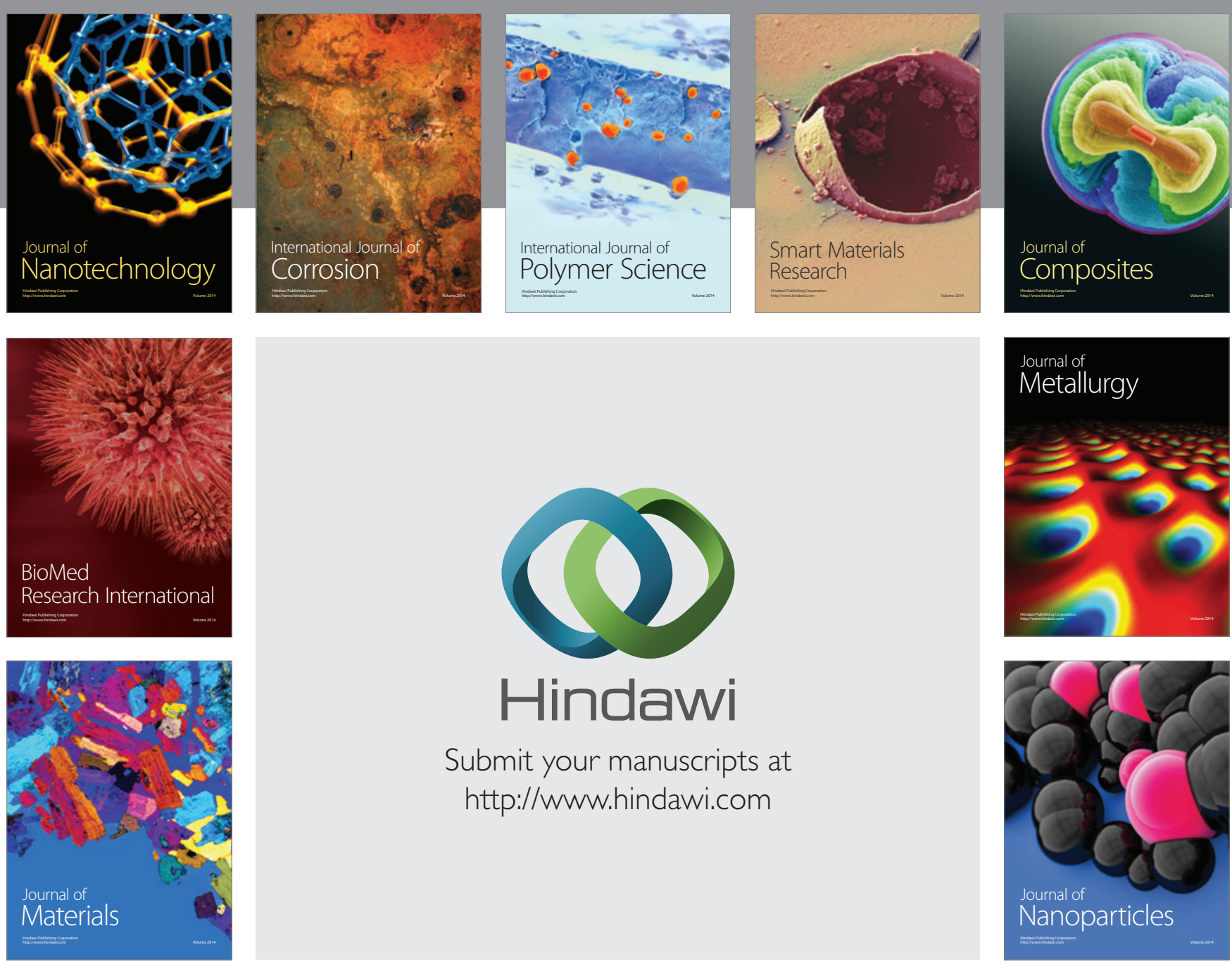

Submit your manuscripts at http://www.hindawi.com
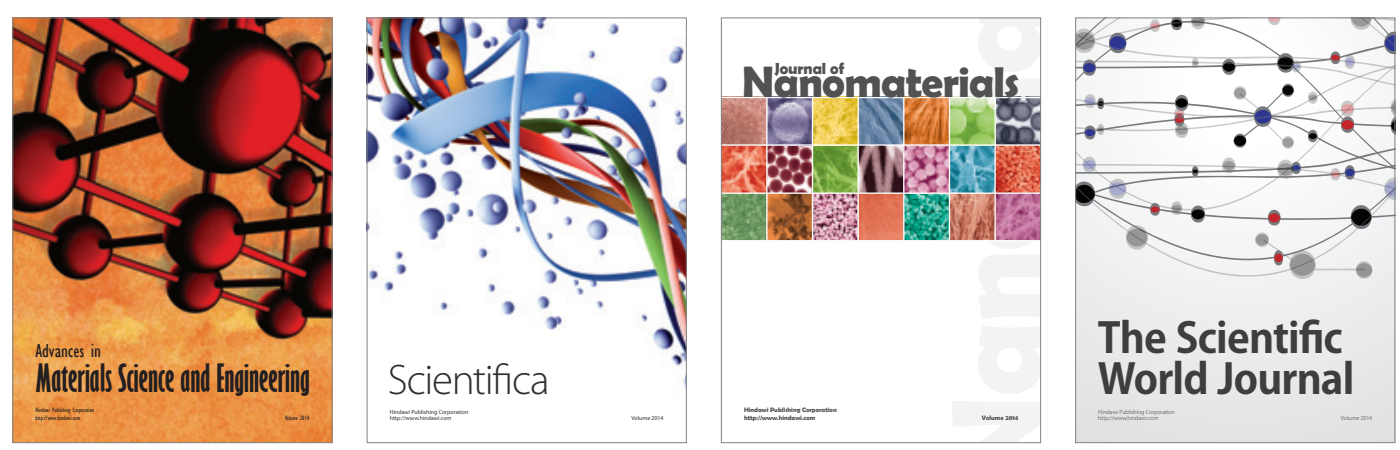

\section{The Scientific World Journal}
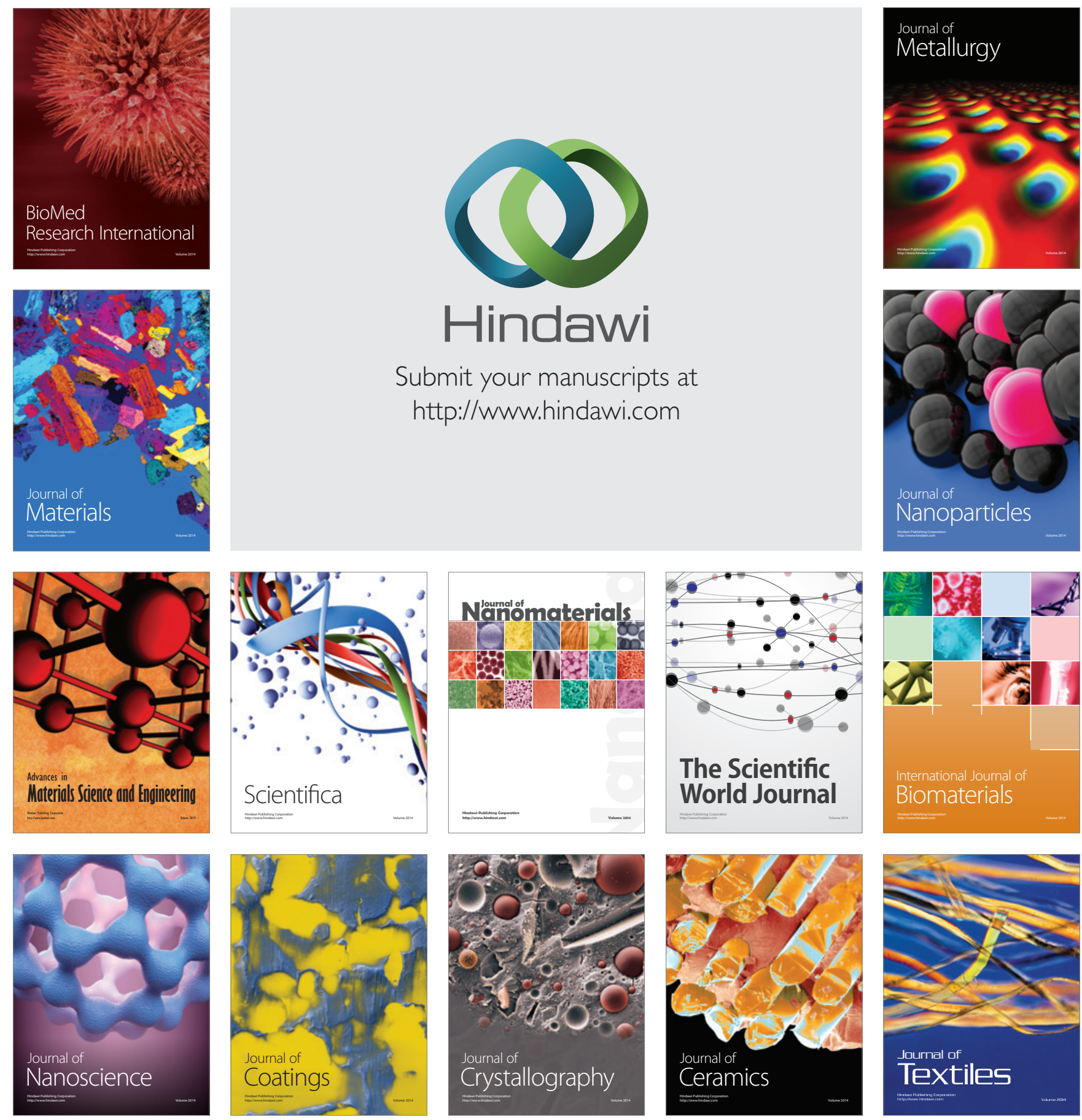